\title{
Knowledge of Shaken Baby Syndrome among Hospital Nurses in Erbil City
}

\author{
Madiha Abass Muhammad; Department of Nursing, College of Nursing, Hawler Medical University, Erbil,
} Iraq. (Correspondence: madiha.abbas@hmu.edu.krd)

Norhan Zeki Shaker; Department of Nursing, College of Nursing, Hawler Medical University, Erbil, Iraq.

Gulala Kream Aziz; Department of Nursing, College of Nursing, Hawler Medical University, Erbil, Iraq.

\section{ABSTRACT}

Background and objectives: Shaken baby syndrome and pediatric abuse head trauma are the most common causes of mortality and morbidity due to physical child abuse. Nurses have a main role in parents' education regarding child abuse prevention. This study aimed to assess nurses' knowledge regarding shaken baby syndrome in Erbil City.

Methods: A descriptive study was conducted at postpartum units, the delivery room and the ward at the Maternity Teaching Hospital, and the inpatient and intensive care units at Rapareen Pediatric Teaching Hospital in 2017 in Erbil City. A purposive sample of 50 nurses was recruited to the study. The data collection was performed using a questionnaire for interviewing the study participants, and the data were analyzed using descriptive and inferential statistical analysis.

Results: The study findings revealed that the majority of the study participants were 19-25 years old and most did not have enough knowledge regarding the signs and symptoms of the shaken baby syndrome (irritability, lethargy, poor feeding breathing problems, uncontrollable crying, vomiting, bluish skin, changes in sleeping pattern, convulsions or seizures and unresponsiveness). Nurses also had insufficient knowledge about the risk factors of this condition. Only a quarter of nurses knew that domestic violence is a risk factor and less than a quarter of them recognized depression and substance abuse of the caregiver as a risk factor. Regarding knowledge of the complications, the study found that a quarter of nurses knew that brain damage, cerebral palsy and blindness are complications of the shaken baby syndrome.

Conclusions: Majority of nurses had poor knowledge about causes, signs, symptoms, risk factors and complications of the shaken baby syndrome.

Keywords: Shaken Baby Syndrome; Nurse; Knowledge.

Received: $24 / 08 / 2020$

Accepted: 02/11/2021

Published: $30 / 05 / 2021$

\section{INTRODUCTION}

Shaken baby syndrome (SBS) and pediatric abuse head trauma continue to be the leading causes of child abuse death and the most common causes of mortality and morbidity due to physical child abuse in the United States [1]. SBS is a severe form of child abuse caused by the violent shaking of an infant or child [2]. When significant rotational acceleration-deceleration forces are applied, the brain is susceptible to shearing of the bridging veins in the subdural space, diffuse axonal injury, contusion and oedema. Shaking an infant or small child can cause bleeding into the back of the eyes [3].and other injuries such as damage to the neck, spine, and eyes [4]. It is dangerous and can cause severe brain damage, blindness, cerebral palsy, mental retardation, behavioural disorders, and impaired motor and cognitive skills. Factors that may increase the risk of inflicting shaken baby syndrome 
include unrealistic expectations of babies, young or single parenthood, stress, domestic violence, alcohol or substance abuse, unstable family situations, depression, and a history of mistreatment as a child [5]. SBS leads to extreme irritability, lethargy, poor feeding, breathing problems, convulsions, vomiting, and pale or bluish skin. Shaken baby injuries usually occur in children younger than 2 years old, but maybe seen in children up to the age of 5 [6]. The data indicate that 1,000 to 1,500 infants per year are shaken and sustain a head injury. According to the information from the Center for Disease Control and Prevention in the United States, of the nearly 2,000 children who die from abuse every year, pediatric abusive head trauma, or SBS is responsible for 10-12 percent of those fatalities. Research also indicates that there is a strong relationship between poverty and child abuse [2]. Nearly all victims of SBS have serious health consequences, such as brain injury, cerebral palsy, seizures and paralysis, and at least one of every four babies who are violently shaken dies. Most adults who admit to shaking a baby say that they became frustrated and upset when the baby would not stop crying [7]. Child Welfare Information [8] suggests solving this problem by teaching parents and nurses about the dangers of shaking a baby, as well as ways to cope with the stresses of caring for a child. These educational programmes are very effective in reducing the incidence of SBS. A systematic review conducted in New York State recommends that all hospitals should offer new parents the option of viewing a video on SBS, including ways to cope with a crying child. Furthermore, it is reported that in developing countries, SBS is one of the leading causes of death [9]. Currently, there are no statistical data about SBS in Iraq and Erbil City, and no published studies about nurses' knowledge of SBS, which is one of the reasons for conducting this study.

\section{METHODS}

The descriptive study design was used to assess nurses' knowledge about shaken baby syndrome. This study was carried out from November 2016 to November 2017 at two public hospitals in Erbil City. These hospitals included Maternity and Rapareen Pediatric Teaching Hospitals. Official permission to conduct the study was obtained from the Erbil General Directorate of Health and the involved hospitals. A purposive research sample consisted of 50 nurses from postpartum units, the delivery room and the ward at the Maternity Teaching Hospital, and the inpatient and intensive care units at Rapareen Pediatric Teaching Hospital in Erbil City. Nurses' oral informed consent was obtained for participation in the study, after confirmation of confidentiality, anonymity, and participants' self-determination by the researcher. The researcher constructed a questionnaire after an extensive review of relevant literature. The questionnaire included three parts. The first part contained sociodemographic information of nurses (age, gender, level of education, hospital setting, duration of experience in nursing and the current unit, participation in training courses and seminars). The second part assessed nurses' knowledge regarding shaken baby syndrome and was divided into five domains (definition, carrying baby criteria, signs and symptoms, risk factors, complications). The third part was designed to assess the source of nurses' knowledge about SBS (nursing school, TV, internet, journals, physicians, seminar, workshop and conference). The knowledge of SBS items was rated and scored according to the two points type scale for all items and scored as 2 and 1 for correct, incorrect answer respectively. After 
obtaining the average of the mean score of each item, the mean score of each domain was calculated, followed by a collection of the mean scores of all knowledge items and divided to two levels (poor and fair) for obtaining levels of nurses knowledge about SBS. These levels were considered to be as a following: poor = $0.72-0.985$, and fair $=0.99-1.25$. Content validity of the questionnaire was checked initially by a panel of five experts specialized in maternity and pediatric nursing and medicine, and all experts' comments regarding the items of the questionnaire were taken into consideration. A pilot study was conducted on a purposive sample of ten nurses and midwives to determine the reliability of the questionnaire. After two weeks the same nurses were selected to assess the same items among nurses from involved hospitals. The participants of the pilot study were included in the main study sample. The reliability of the tool was computed, and the correlation of 0.86 was statistically adequate. The collected data were analyzed using the Statistical Package for Social Science (SPSS, Version 20). The descriptive statistical analysis included frequency, percentage, mean, and standard deviation, while chi-square and Fisher exact test were used for inferential analysis. The P-value of $\leq 0.05$ was considered significant.

\section{RESULTS}

Table 1 shows that $44 \%$ of participants were within the age group of 19-25 years. The mean score and standard deviation (SD) of their age were $26.54 \pm 5.64$. The highest percentage $(64 \%)$ of the sample were nursing institute graduates, and $64 \%$ of nurses were working at the Maternity Teaching Hospital (post-partum unit - 12\%, delivery room - $12 \%$, inpatient ward - $46 \%$, ICU - 30\%. The mean score and standard deviation of nurses' experience were
$7.17 \pm 5.12$ years. Regarding nurses' professional background, $8 \%$ of nurses participated in a training course related to SBS, and for the highest percentage of nurses' $(66 \%)$, the source of information was the Internet. Table 2 shows the nurses' knowledge about the definition of SBS and the questions included the following: SBS is an injury caused by a sudden jerking of the head $(1.24 \pm 0.43)$, SBS is abusive head trauma (1.28 \pm 0.45$)$, SBS results in a subdural hematoma \& retinal haemorrhage on the brain's surface $(1.22 \pm 0.42)$. The mean score of nurses' knowledge regarding the definition of SBS was 1.24. This table shows that most of the nurses answered the questions incorrectly. Table 3 indicates that the mean score of nurses' knowledge about crying baby was 1.18 , showing that the majority of nurses did not know correct answers to the questions in this area. Table 4 shows that the mean score of nurses' knowledge about signs and symptoms of SBS was 1.22. This table also clarifies that the majority of nurses did not have sufficient knowledge of the signs and symptoms of SBS. Table 5 shows that the mean scores of nurses' knowledge about risk factors and complications of SBS were 1.2 and 1.1 respectively. This table shows that the majority of nurses answered the risk factors and complications of SBS questions incorrectly. Table 6 indicates a statistically not significant association between nurses' level of knowledge about SBS, nurses' education, and participation in training courses, and a statistically significant association with duration of experience in nursing. 
Table 1: Demographic data of nurses, sample $n=50$

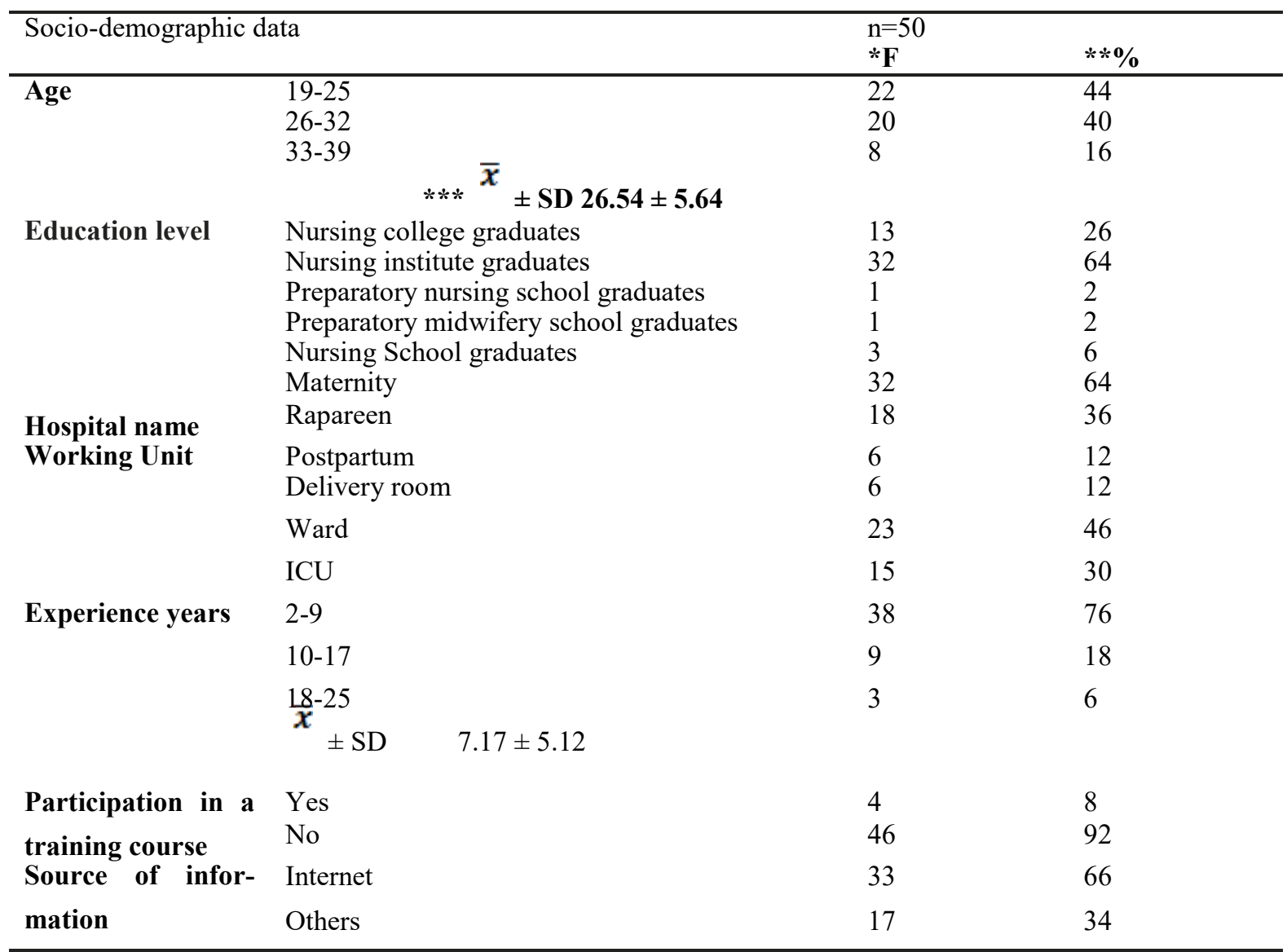

*Frequency $\quad * *$ Percentage $\quad * * *$ Mean \pm Standard Deviation

Table 2: Assessment of nurse's knowledge about the definition of the shaken baby syndrome.

\begin{tabular}{llll}
\hline & $\mathbf{n = 5 0}$ & & \\
Nurses' knowledge about the definition of SBS & Correct & Incorrect & $\overline{\boldsymbol{x}}$ \\
& $\mathbf{F ~ ( \% )}$ & $\mathbf{F}(\mathbf{\%})$ & \\
& & & \\
\hline SBS is an injury caused by a sudden jerking of the head. & $12(24)$ & $38(76)$ & $1.24 \pm 0.43$ \\
SBS is abusive head trauma. & $14(28)$ & $36(72)$ & $1.28 \pm 0.45$ \\
SBS results in a subdural hematomas \&retinal haemorrhage & $11(22)$ & $39(78)$ & $1.22 \pm 0.42$ \\
on the brain's surface. & & & \\
& & & \\
Total mean score & $\mathbf{1 . 2 4}$ & & \\
\end{tabular}


Table 3:Assessment of nurses' knowledge about crying baby criteria

\begin{tabular}{|c|c|c|c|}
\hline Nurses' knowledge about crying baby criteria & $\begin{array}{l}\mathbf{n}=\mathbf{5 0} \\
\text { Correct } \\
\mathbf{F}(\%)\end{array}$ & $\begin{array}{l}\text { Incorrect } \\
\text { F (\%) }\end{array}$ & $\bar{x}_{ \pm \mathrm{SD}}$ \\
\hline Infants cry more often in the late afternoon and evening. & $11(22.0)$ & $39(78)$ & $1.22 \pm 0.42$ \\
\hline Infant crying increases in the first few weeks of life and reaches a peak in the first 2 or & $9(18)$ & $41(82)$ & $1.18 \pm 0.38$ \\
\hline $\begin{array}{l}3 \text { months before getting less. } \\
\text { Sometimes a healthy infant cries unexpectedly or without a clear reason. } \\
\text { When an infant cries it is not always a sign that something is wrong. } \\
\text { Sometimes a crying infant can look like she/he is in pain even when they are not. } \\
\text { Sometimes healthy infants can cry for } 5 \text { or more hours a day. } \\
\text { It is ok to walk away from a crying infant when his or her crying becomes very frus- }\end{array}$ & $\begin{array}{l}7(14) \\
6(12) \\
10(20) \\
10(20) \\
13(26)\end{array}$ & $\begin{array}{l}43(86) \\
44(88) \\
40(80) \\
40(80) \\
37(74)\end{array}$ & $\begin{array}{l}1.14 \pm 0.35 \\
1.12 \pm 0.33 \\
1.2 \pm 0.40 \\
1.2 \pm 0.40 \\
1.26 \pm 0.44\end{array}$ \\
\hline $\begin{array}{l}\text { trating. } \\
\text { SB is not a good way to help a baby stop crying. } \\
\text { Total mean score }\end{array}$ & $\begin{array}{l}6(12) \\
\mathbf{1 . 1 8}\end{array}$ & $44(88)$ & $1.12 \pm 0.33$ \\
\hline
\end{tabular}

Table 4: Assessment of nurses' knowledge about signs and symptoms of the shaken baby syndrome.

\begin{tabular}{|c|c|c|c|}
\hline Signs and symptoms of the shaken baby syndrome & $\begin{array}{l}\mathbf{n}=\mathbf{5 0} \\
\text { Correct } \\
\text { F (\%) }\end{array}$ & $\begin{array}{l}\text { Incorrect } \\
\text { F (\%) }\end{array}$ & $\bar{x}^{\bar{x}} \pm$ SD \\
\hline $\begin{array}{l}\text { Become extremely irritable. } \\
\text { Become lethargy. } \\
\text { Become poor feeding. } \\
\text { Will complain from breathing problems. } \\
\text { Will complain from uncontrollable crying. } \\
\text { Will complain from vomiting. } \\
\text { Become pale or bluish skin. } \\
\text { Will complain from significant changes in sleeping patterns. } \\
\text { Cannot be consoled. } \\
\text { Will complain from convulsions or seizures. } \\
\text { In more severe cases of SBS, the babies may be unresponsive. } \\
\text { Total mean score }\end{array}$ & $\begin{array}{l}11(22.0) \\
12(24) \\
14(28) \\
16(32) \\
15(30) \\
15(30) \\
9(18) \\
9(18) \\
9(18) \\
7(14) \\
7(14) \\
1.22\end{array}$ & $\begin{array}{l}39(78) \\
38(76) \\
36(72) \\
34(68) \\
35(70) \\
35(70) \\
41(82) \\
41(82) \\
41(82) \\
43(86) \\
43(86)\end{array}$ & $\begin{array}{l}1.22 \pm 0.42 \\
1.24 \pm 0.43 \\
1.28 \pm 0.45 \\
1.32 \pm 0.47 \\
1.30 \pm 046 \\
1.30 \pm 046 \\
1.18 \pm 0.38 \\
1.18 \pm 0.38 \\
1.18 \pm 0.38 \\
1.14 \pm 0.35 \\
1.14 \pm 0.35\end{array}$ \\
\hline
\end{tabular}

Table 5: Assessment of nurses' knowledge about risk factors and complication of the shaken baby syndrome.

\begin{tabular}{|c|c|c|c|}
\hline Risk Factors of SBS & $\begin{array}{l}\mathbf{n}=\mathbf{5 0} \\
\text { Correct } \\
\text { F (\%) }\end{array}$ & $\begin{array}{l}\text { Incorrect } \\
\text { F (\%) }\end{array}$ & $\bar{x}_{ \pm \mathrm{SD}}$ \\
\hline Unrealistic expectations of babies & $10(20)$ & $40(80)$ & $1.2 \pm 0.40$ \\
\hline Domestic violence & $12(24)$ & $38(76)$ & $1.24 \pm 0.43$ \\
\hline Depression, substance abuse & $11(22.0)$ & $39(78)$ & $1.26 \pm 0.44$ \\
\hline Family history of SBS. & $11(22.0)$ & $39(78)$ & $1.22 \pm 0.41$ \\
\hline Unstable family situations & $8(16)$ & $42(84)$ & $1.16 \pm 0.37$ \\
\hline Mother's depression & $10(20)$ & $40(80)$ & $1.2 \pm 0.40$ \\
\hline A history of mistreatment as a child & $8(16)$ & $42(84)$ & $1.16 \pm 0.37$ \\
\hline Total mean score & 1.2 & & \\
\hline \multicolumn{4}{|l|}{ Complications of SBS } \\
\hline SBS causes severe brain damage & $4(8)$ & $46(92)$ & $1.08 \pm 0.27$ \\
\hline SBS causes cerebral palsy & $4(8)$ & $46(92)$ & $1.08 \pm 0.27$ \\
\hline SBS causes blindness & $5(10)$ & $45(90)$ & $1.10 \pm 0.30$ \\
\hline SBS causes behavioural disorders & $4(8)$ & $46(92)$ & $1.08 \pm 0.27$ \\
\hline SBS causes impaired motor and cognitive skills & $10(20)$ & $40(80)$ & $1.2 \pm 0.40$ \\
\hline SBS caused damage to the neck and spine & $4(8)$ & $46(92)$ & $1.08 \pm 0.27$ \\
\hline Total mean score & 1.1 & & \\
\hline
\end{tabular}


Table 6: Association between nurse levels of shaken baby syndrome knowledge and education, age.

\begin{tabular}{|c|c|c|c|c|c|}
\hline \multirow[b]{3}{*}{ Nurses criteria } & & \multicolumn{4}{|c|}{ Nurses knowledge levels $(n=50)$} \\
\hline & & \multirow{2}{*}{$\begin{array}{l}\text { Fair* } \\
\text { F (\%) }\end{array}$} & \multirow{2}{*}{$\begin{array}{l}\text { Poor** } \\
\text { F (\%) }\end{array}$} & \multirow{2}{*}{$\begin{array}{l}\text { Total } \\
\text { F (\%) }\end{array}$} & \multirow[t]{2}{*}{ P-value } \\
\hline & & & & & \\
\hline \multirow{3}{*}{ Education level } & Institute & 29 & 3 & 32 & \multirow{3}{*}{ NS*** } \\
\hline & Preparatory nursing School & 1 & 0 & 1 & \\
\hline & Preparatory Midwifery & 1 & 0 & 1 & \\
\hline \multirow{3}{*}{$\begin{array}{l}\text { Duration of Experi- } \\
\text { ence years }\end{array}$} & $2-9$ & 35 & 3 & 38 & \multirow{3}{*}{$\mathrm{HS} * * * *$} \\
\hline & $10-17$ & 8 & 1 & 9 & \\
\hline & $18-25$ & 1 & 2 & 3 & \\
\hline Participation in train- & Yes & 2 & 2 & 4 & 0.06 \\
\hline
\end{tabular}

$*$ Poor $=0.72-0.98, * *$ Fair $=0.99-1.25, * * * N S=$ Not Significant, $* * * *$ HS=High Significant

Figure 1 represents the mean score of nurses' knowledge about SBS in its fours domains was low.

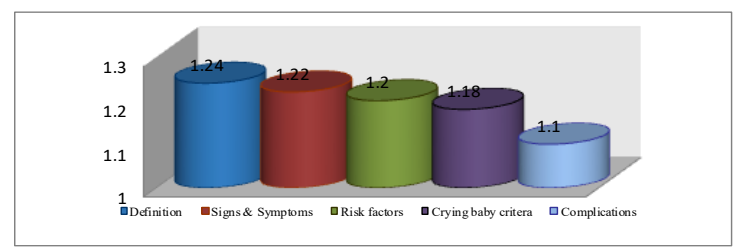

Fig.1 Distribution of nurses according to mean scores of 4 domains of the shaken baby syndrome knowledge.

Figure 2 indicates that SBS knowledge of the majority of nurses (88\%) was poor and that $12 \%$ of study participants had a fair

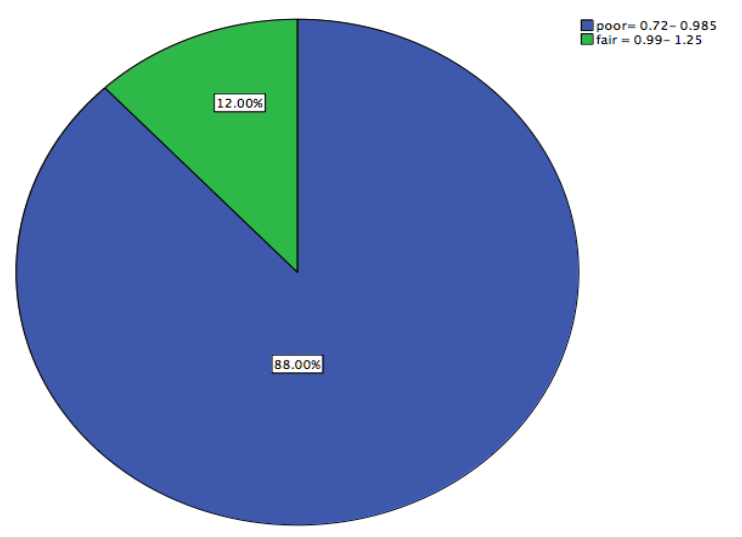

Fig: 2 Overall levels of nurses' knowledge about the shaken baby syndrome.

\section{DISCUSSION}

Analysis of demographic characteristics revealed that the highest percentage of nurses were in the age group of 19-25 years and nursing institute graduates. This finding is in contrast to a study carried out Brubaker in 2016, which evaluated nurses' knowledge of shaken baby syndrome prevention after exposure to "Period of Purple Crying" Program, and found that lowest percentage of nurses had diploma certificate [10]. The current study indicates that few nurses participated in the training course and the Internet was the main source of their information about SBS. As we know the nurse is a primary care provider to infants, and a parent educator before the child is discharged from the hospital or when they come for well-child visits and should therefore identify SBS and its consequences, risk factors, signs and symptoms. Testing nurses' knowledge in the current study was divided into four domains; the first domain evaluated nurses' knowledge of the definition of SBS. This study reveals that more than two-thirds of nurses responded incorrectly to SBS definition items, which 
reflects nurses' poor knowledge about SBS. Concerning nurses' knowledge about crying baby criteria, the current study shows that majority of nurses replied incorrectly to most of crying baby criteria items, with highest percentages only in two items (infant cries is not always a sign that something is wrong, and shaking baby is not a good way to help a baby stop crying), confirming that nurses have knowledge deficit in this regard. Bravo states that every infant who is discharged from a newborn nursery should be sent home with parents who are prepared for neonatal care. Through educational programs, parents can receive positive guidelines to help them to cope with children who have special needs, need extra attention, or simply cry for long periods [11], and nurses are responsible for educating of mothers before discharge. Adding to that, SBS often occurs after shaking in response to crying attacks [12]. This implicates the importance of nurses' knowledge about crying baby. Regarding nurses knowledge about signs and symptoms of SBS, the finding of the present study reveals that majority of nurses did not know the signs and symptoms of SBS and gave incorrect answers to the questionnaire items (irritable, lethargy, poor feeding, breathing problems, uncontrollable crying, vomiting, bluish skin, changes in sleeping patterns, convulsions or seizures and unresponsive). This finding reveals nurses' poor information about SBS symptoms when it is expected from the nurses to discover abused and maltreated children in addition to their responsibility in educating parents about SBS prevention and child safety. Regarding nurses' knowledge about risk factors of SBS, the current study found that about a quarter of nurses know that domestic violence is a risk factor for SBS. This is compatible with the study done in the United States by
Steven et al, which mentions that caretakers at risk of abusive behaviour generally have unrealistic expectations of their children and may exhibit a role reversal whereby caretakers expect their needs to be met by the child [13-14]. In the current study, less than a quarter of nurses recognized that depression and substance abuse of caregiver is a risk factor for SBS of children. This is in agreement with a study, which shows that the most common risk factor for perpetrators, most frequently parents, is the inability to cope with stress, substance abuse, infants born to mothers who suffer from depression or consume alcohol during pregnancy [15]. Regarding nurses' knowledge about complications of SBS, the current study found that about a quarter of nurses know that brain damage, cerebral palsy and blindness are complications of SBS. This result is supported by Walls and Castiglia who mention that the main complications of SBS involve impaired mental, physical, and sensory development, visual impairments, blindness, seizure disorder, developmental delays, motor dysfunction, spasticity, cerebral palsy [16]. Regarding the overall level of nurses' knowledge of SBS, the majority of nurses had poor knowledge about SBS.

\section{CONCLUSION}

According to the discussion and interpretation of the study findings, researchers concluded that majority of nurses don't know the signs and symptoms, risk factors, complications of SBS, and overall, the majority of nurses have poor knowledge level about SBS. Researchers recommend establishing a health education program for nurses in hospitals to raise awareness of all aspects of SBS. 
CONFLICT OF INTERESTS

There is no conflict of interest and no financial support for any of the authors.

\section{REFERENCE}

[1] Ronald G, Marilyn B, Takeo F, Jocelyn C, Nicole C, and Rollin B. Do educational materials change knowledge and behavior about crying and shaken baby syndrome? A randomized controlled trial. Canadian Medical Association Journal, 2014; 180(7): 727-33.

[2] Centers for Disease Control (CDC), what is Shaken Baby Syndrome? www.cdc.gov/ concussion/headsup/sbs/html, 2015.

[3] Christian, C, Block, R. Abusive head trauma in infants and children. Pediatrics, Official Journal of American Academy of Pediatrics, 2009; 123(5), 1409-11. DOI: https:// doi.org/10.1542/peds.2009-0408.

[4] Arabinda K Choudhary, Ramsay Ishak, Thomas T Zacharia, Mark S Dias Affiliations. Imaging of spinal injury in abusive head trauma: a retrospective study. Pub Med Pediatr Radiol. DOI: 2015 May;45 (5):784. DOI: 10.1007/s00247-015-3335-7.

[5] National MCH Center for Child Death Review, Child abuse and neglect fact sheet, http://www.childdeathreview.org/ causesCAN.htm, 2011.

[6] Lee LM, Teutsch SM, Thacker SB, St. Louis $\mathrm{ME}$. (Eds). Principles and practice of public health surveillance. Oxford Scholarship Online; 2010. DOI: 10.1093/acprof:oso/ 9780193572922.001.0001.

[7] Sharyn E Parks, Scott R Kegler, Joseph L Annest, James A Mercy Characteristics of fatal abusive head trauma among children in the U.S. 2003-2007: An application of the CDC operational case definition to national vital statistics data. Injury Prevention, 2011;18 (3), p.193-9.

[8] Parks Sh, Kegler S, Annest J, Mercy J, Characteristics of fatal abusive head trauma among children in the U.S. 2003-2007: An application of the CDC operational case definition to national vital statistics data. Injury Prevention, 2011; 18(3), 193-9.

[9] Child Welfare Information Gateway, 2011. Child abuse and neglect fatalities, Statistics and interventions. Washington, DC: U.S. Department of Health and Human Services, Children's Bureau. http://www.child re.gov/ pubs/factshsheets/fatality.cfm 2009.
[10] Maguire $S$, Watts $P$, Shaw A, Holden $S$, Taylor R, Watkins $W$, and et al, Retinal haemorrhages and related findings in abusive and non-abusive head trauma: a systematic review. Eye, 2013; 27(1), 28-36.

[11] Brubaker-Vincent, C. L., and Evaluation of Nurses' Knowledge of "Period of PURPLE Crying" Program: Shaken Baby Syndrome Prevention, DNP Projects, 76. https:// uknowledge.uky.edu/dnp_etds/76, 2016.

[12] Bravo, M. S., Shaken baby syndrome: The implementation and evaluation of an education program for parents, Journal of Nursing Education and Practice, 2014; 4(9), 91-9.

[13] Ronald G, do educational materials change knowledge and behavior about crying and shaken baby syndrome? A randomized controlled trial, Canadian Medical Association Journal, 2009; 180(7), 727-30.

[14] Kairys S, Alexander R, Block R, Everett D, Hymel K, Jenny $C$, and et al, Shaken baby syndrome: Rotational cranial injuriestechnical report, Pediatrics, 2001;108(1), 206-10.

[15] Altimier, L., Shaken baby syndrome, Journal of Perinatal \& Neonatal Nursing, 2008; 22 (1), 68-76.

[16] Walls, C., Shaken Baby Syndrome education: A Role for Nurse Practitioners Working with Families of Small Children, Journal of Pediatric Health Care, 2006; 20(5), 30410. 